\title{
A INFLUÊNCIA DOS TIPOS PSICOLÓGICOS NO RELACIONAMENTO DE CASAL
}

\section{The Influence of Psychological Types on Couple Relationship}

\author{
Prof. Ms. Tommy Akira Goto ${ }^{1}$ \\ Helder Kamei ${ }^{2}$ \\ Simone Fujii ${ }^{3}$
}

\section{Resumo}

O presente trabalho visa verificar como os tipos psicológicos influenciam no cotidiano de um casal e como se dá a manutenção deste vínculo no dia-a-dia, tendo como teoria de base os tipos psicológicos descritos por Carl G. Jung. Analisa a dinâmica dos tipos psicológicos sob duas perspectivas: a intrapsíquica (dinâmica entre a função psicológica principal, as auxiliares e a função inferior) e interpsíquica (dinâmica entre os tipos psicológicos dos cônjuges). O método consiste em um estudo de caso, tendo um casal como sujeito de pesquisa. Para pesquisar a dinâmica do casal, utilizamos três fontes de dados: os resultados das aplicações do QUATI (Questionário de Avaliação Tipológica), o relato da entrevista de cada cônjuge separadamente e a análise vivencial dos sujeitos durante as entrevistas. No nosso estudo de caso, entretanto, os resultados obtidos pelo QUATI não foram tipos opostos ideais. A nossa compreensão do caso é a de que embora os cônjuges não sejam opostos tipológicos ideais, eles funcionam como opostos intrapsíquicos, uma vez que suas atitudes e funções utilizadas são complementares em muitas situações das diversas áreas da vida humana. Observamos também uma relação simbiótica, entretanto a projeção que um cônjuge faz ao outro não é de suas partes sombrias e sim de suas potencialidades latentes, de maneira que a relação torna-se criativa, apesar de conflitiva.

Palavras-chave: Tipologia; Personalidade; Relacionamento conjugal; Relações interpessoais.

1 Professor da PUC-Minas - Câmpus Poços da Caldas. Doutorando em Psicologia pela PUCCAMP/SP.

2 Psicólogo. Universidade São Marcos. Rua César Guimarães, 73 casa 16 - bairro Jardim da Glória. São Paulo - SP. CEP: 01545-070. E-mail: helder.psi@ig.com.br

3 Psicóloga. Universidade São Marcos. 
Abstrac

The present work aims at verifying how the psychological types influence on a couple's daily routine and how this link is kept day by day, having as fundament the psychological types theory described by Carl G. Jung. It analyses the psychological type's dynamic under two perspectives: intra-psycho (dynamic among principal conscious function, auxiliaries and inferior function) and inter-psycho (dynamic between the psychological types of each spouse. The method consists of a study of case, having a couple as research subjects. To research the couple's dynamic, we use three data source: the results of QUATI application (Questionnaire of Typological Evaluation), each one's reporting of their own interviews and the couple's ongoing analyses during the interviews. However, in our study of case, the results obtained by QUATI were not perfect opposite types. Our comprehension of the case is that, despite the fact that the spouses are not perfect psychological types, they work as opposite intra-psycho, and in addition the behavior and functions they use are complementary in many situations of several areas of the human life. We also observe a symbiotical relation, however, the projection that each spouse does to the other is not of shady parts but of their latent potentialities, therefore the relationship becomes creative, despite being conflictive.

Keywords: Typology; Personality; Marital relationship; Interpersonal relations.

\section{Introdução}

Em “O Banquete”, Platão narra um antigo mito grego sobre a origem do homem e da mulher. Nele, inicialmente os seres humanos eram andróginos. Por desafiarem Zeus, estes são divididos ao meio, e assim surgem os gêneros humanos. A partir deste momento, cada metade tem 0 desejo de encontrar a sua outra metade, a fim de se fundir em um único ser, de se religar, de se reunir em um só. Cada ser humano busca reencontrar a totalidade primordial e resgatar a unidade perdida. Essa incansável busca do ser humano foi que nos motivou a buscar um maior conhecimento e maior compreensão sobre este fenômeno psicológico.

O presente artigo baseia-se em uma pesquisa realizada na Universidade São Marcos, intitulada Em busca da unidade perdida: a influência dos tipos psicológicos na dinâmica de casal, e tem como objetivo apresentar como os tipos psicológicos influenciam na dinâmica do relacionamento conjugal, fundamentando-se na teoria dos tipos psicológicos elaborada por Carl Gustav Jung e sendo explorada por meio de um estudo de caso. Para uma melhor compreensão dos termos envolvidos, podemos dizer que a teoria dos tipos psicológicos só pode ser compreendida segundo a estrutura da personalidade, e o relacionamento conjugal por meio da dinâmica entre os arquétipos animus e anima. Esses conceitos se inter-relacionam e estão inseridos em um processo mais amplo, que Jung denominou individuação.

Na psicologia junguiana, a personalidade é entendida como um todo e é denominada psi- que. Para Jung (citado por Hall \& Nordby, 1980), a psique possui uma estrutura, cujos componentes interagem uns com os outros e com o mundo exterior, e subdivide-se em diversos níveis, dentre os quais se distingue a consciência e o inconsciente. Segundo Jung (1995), o inconsciente se estrutura em duas camadas: uma formada pelo inconsciente pessoal e outra pelo inconsciente coletivo, que seria um inconsciente impessoal ou transpessoal. $\mathrm{O}$ inconsciente pessoal contém percepções dos sentidos que não ultrapassaram o limiar da consciência por falta de intensidade, além de lembranças perdidas, reprimidas ou recalcadas, evocações dolorosas, correspondendo àquilo que Jung chamou de sombra. Por outro lado, o inconsciente coletivo é totalmente universal, pois contém as imagens primordiais, ou seja, as formas mais antigas da imaginação humana, imagens humanas universais e originárias, as quais Jung denominou de arquétipos, e que jazem adormecidas nas camadas mais profundas do inconsciente.

Na imaginação de cada ser humano há uma aptidão hereditária de ser como era nos primórdios. No entanto, Jung (1995, p. 57) alerta para uma diferença importante: "Isso não quer dizer, em absoluto, que as imaginações sejam hereditárias; hereditária é apenas a capacidade de ter tais imagens, o que é bem diferente". Os arquétipos mais importantes na formação de nossa personalidade são: a persona, a sombra, anima e animus e 0 self.

A persona é o arquétipo da conformidade. A palavra persona era usada originalmente para denominar a máscara utilizada por atores no teatro. Na psicologia junguiana, o arquétipo da perso- 
na dá ao indivíduo a possibilidade de compor uma personagem que necessariamente não seja ele mesmo. É a máscara ostentada publicamente para provocar uma impressão favorável à sociedade, de modo que ela o aceite. Ela nos torna capazes de conviver de forma amistosa com as pessoas, inclusive com as que nos desagradam. É a base da vida social e comunitária.

Muitas pessoas levam vidas duplas, uma dominada pela persona e outra que satisfaz as demais necessidades psíquicas. Entretanto, uma pessoa pode usar mais de uma máscara, porém, todas as máscaras, em conjunto, constituem a sua persona.

Além da persona, um outro arquétipo fundamental é a sombra. Conforme lembra Henderson (1997), o conceito de sombra ocupa lugar vital na psicologia analítica. A sombra projetada pela mente consciente do indivíduo contém os aspectos ocultos, reprimidos e desfavoráveis da personalidade, mas não representa simplesmente o inverso do ego consciente. "Assim como o ego contém atitudes desfavoráveis e destrutivas, a sombra possui algumas boas qualidades - instintos normais e impulsos criadores" (Henderson, 1997, p. 118).

No entendimento de von Franz (1997), a sombra não é o todo da personalidade inconsciente, pois consiste de aspectos que pertencem sobretudo à esfera pessoal e que poderiam também ser conscientes. A sombra contém tendências e impulsos que negamos existir em nós, mas que conseguimos ver perfeitamente nos outros, como egoísmo, preguiça, negligência, fantasias irreais, intrigas, tramas, indiferença, covardia, apego ao dinheiro e aos bens etc. Continua von Franz (1997, p. 168): "Se você se enche de raiva quando um amigo lhe aponta uma falta, pode estar certo que aí se encontra uma parte da sua sombra, da qual você não tem consciência".

A sombra é o arquétipo que possui a maior quantidade de natureza animal. Contém os instintos básicos e é fonte de intuições realistas e de respostas adequadas, importantes para a sobrevivência. É o arquétipo mais poderoso e potencialmente o mais perigoso de todos.

Em contraposição ao inconsciente, encontra-se a consciência, que, segundo Jung (1988), é sempre consciência do eu. Nesse sentido, o Eu (ou Ego) é o sujeito da consciência, sendo ao mesmo tempo condição de consciência.
Na compreensão de Jung (2000), os processos inconscientes funcionam de forma compensatória em relação à consciência, enfatizando que o consciente e 0 inconsciente não se encontram em oposição, pois se complementam mutuamente formando uma totalidade, à qual denominou de self (si-mesmo). Von Franz (1997) explica que Jung chamou de self o centro organizador de onde emana esta ação reguladora, descrevendo-o como a totalidade absoluta da psique, para diferenciá-lo do ego, que constitui apenas uma pequena parte da psique. Assim, o self é, a um só tempo, o núcleo e a totalidade da psique e neste sentido, não podendo ser confundido como sinônimo de inconsciente. Ele pode ser o inconsciente quando polarizado com o Ego, mas é também o todo por incluir o Ego. Enquanto o Ego é o sujeito da consciência, o self ou si-mesmo é o sujeito de toda a psique.

No nível pessoal, a consciência é constituída pelos desejos, temores, esperanças e ambições de caráter pessoal. Os processos inconscientes constituem-se de motivos pessoais que a consciência desconhece, mas que afloram nos sonhos ou são significados de situações cotidianas negligenciadas, de afetos que não nos permitimos e críticas a que nos furtamos.

Por meio do autoconhecimento, tornamonos mais conscientes de nós mesmos, reduzindo assim a camada do inconsciente pessoal que recobre o inconsciente coletivo, colocando o indivíduo em uma comunhão incondicional, obrigatória e indissolúvel com o mundo.

Há uma possível meta para cada ser humano, uma destinação, à qual Jung (2000) denomina caminho da individuação. Podemos traduzir individuação como tornar-se si mesmo (Verselbstung) ou o realizar-se do si mesmo (Selbstverwirklichung). Jung (2000) enfatiza, no entanto, que individuação nada tem a ver com individualismo, uma vez que a individuação significa a realização melhor e mais completa das qualidades coletivas do ser humano. Esta realização do self consiste em um processo de desenvolvimento psicológico que faculta a realização das qualidades individuais dadas, tornando-se o ser único que de fato é. No entanto, o ser humano é composto de fatores puramente universais, sendo, portanto, coletivo e de modo algum oposto à coletividade. $\mathrm{O}$ que ocorre é que os fatores universais sempre se apresentam de forma individual, e por isso Jung denomina este 
processo de individuação. Complementando essa idéia, podemos dizer, conforme Vargas (1981, p. 24), que "todo o indivíduo possui uma tendência para o desenvolvimento, o que o leva na vida a buscar realizar suas potencialidades".

O processo de individuação consiste na harmonização do consciente com o self, este núcleo psíquico, centro da personalidade. Vargas (1981, p. 26) ressalta que o "processo de individuação resulta então do interjogo constante entre consciente e inconsciente sem que um reprima ou possua o outro".

\section{Sobre os Tipos Psicológicos}

O modelo junguiano de tipologia nasceu de uma ampla revisão histórica, de um estudo detalhado abordado pela Literatura, Mitologia, Estética, Filosofia e pela Psicopatologia, e é considerado um dos principais frutos do desenvolvimento dos estudos sobre o inconsciente. Segundo Staude (1988, citado por Zacharias, 2006), a obra "Tipos Psicológicos" foi a primeira obra fundamental de Jung após o período de rompimento com Freud, da conseqüente crise e da análise extensa dos conteúdos inconscientes.

Jung percebeu que as pessoas possuíam diferenças individuais de personalidade. Essas diferenças típicas resultam em dois tipos psicológicos: introvertido e extrovertido. A introversão e a extroversão são formas psicológicas de adaptação. No primeiro caso, o movimento da energia psíquica é direcionada para o mundo interior e no segundo caso para o mundo exterior. Como postula Jung (citado por Sharp, 1987):

A introversão costuma se caracterizada por uma natureza vacilante, meditativa, reserva- da, que espontaneamente se mantém isolada dos outros, recua diante dos objetos e está sempre um pouco na defensiva. A extroversão, pelo contrário, costuma ser caracterizada por uma natureza saliente, franca e obsequiosa, que se adapta com facilidade às situações propostas, estabelece rapidamente ligações e, pondo de lado qualquer tipo de apreensão, arrisca-se, com despreocupada confiança, as situações desconhecidas. (p. 13)

Por meio de suas observações, Jung identificou quatro fórmulas de atividades da psique em relação ao mundo, denominando-as de funções da consciência. Essas funções foram divididas em dois grupos: as funções de percepção - sensação e intuição - que são as duas maneiras de se receber informações sobre algo; e as funções de julgamento - sentimento e pensamento - as duas maneiras de se avaliar algo. Todas estas funções são necessárias, conforme explica Jung (citado por Sharp, 1987):

Para que haja uma perfeita orientação, as quatro funções devem contribuir igualmente: o pensamento deve facilitar a cognição e o julgamento; o sentimento deve nos dizer como e em que grau uma coisa é ou não importante para nós; a sensação deve transmitir a realidade concreta através da visão, da audição, do paladar, etc; e a intuição deve capacitarnos a pressentir as possibilidades ocultas, que se encontram em segundo plano, já que estas também fazem parte do quadro completo de uma determinada situação (p.15).

Para uma melhor visualização do que expomos até o presente momento, vejamos um exemplo. No diagrama abaixo, a função principal é o pensamento, a função auxiliar é a sensação, a intuição é a terceira função e o sentimento constitui a função inferior. 


\section{Figura 1. Modelo Tipológico Cruciforme.}

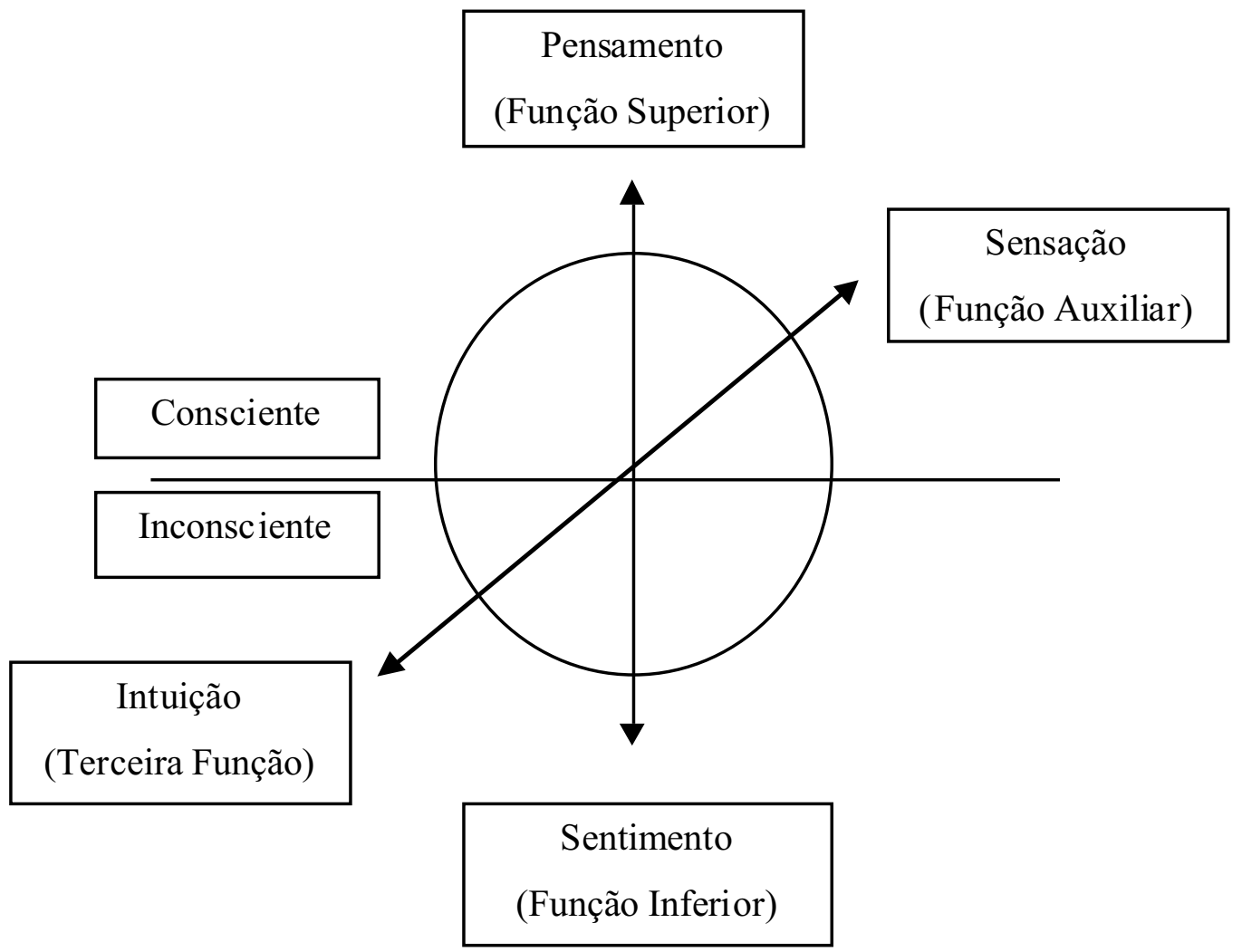

Fonte: adaptado de Zacharias (2006, p. 72)

Nesse exemplo, podemos observar que há uma função superior e uma inferior, no entanto, isso não implica em um julgamento de valor. A função superior é aquela que uma pessoa usa com mais freqüência e a função inferior refere-se àquela função utilizada em menor grau pelo indivíduo.

A segunda função mais utilizada é chamada de função auxiliar, e a natureza desta (percepção ou julgamento) se difere da função dominante. Por exemplo, quando a função pensamento for dominante, o sentimento não poderá ser a função secundária e vice-versa, pois ambos são funções de julgamento.

A função menos utilizada é denominada função inferior, que é aquela que resiste particularmente à integração dentro da consciência, também chamada de quarta função. Na tipologia de Jung (citado por Sharp, 1987), "A essência da função inferior é a autonomia: ela é independente, ela ataca, fascina e nos rouba o controle; dá-nos a impressão de que já não somos donos de nós mesmos, de que já não podemos mais distinguir nossa pessoa da dos outros" (p. 22).
No modelo acima, a função inferior ou a quarta função possui invariavelmente a mesma natureza da função dominante. Por exemplo, se a função do pensamento for a mais desenvolvida, então, a função menos desenvolvida ou inferior será a do sentimento. Se a sensação que é uma função perceptiva for a dominante, então a intuição será a quarta função, e assim por diante.

\section{Tipologia e Relacionamento Amoroso}

Para compreender o relacionamento amoroso na psicologia junguiana, dois arquétipos são fundamentais: a anima e o animus. A anima representa o componente feminino na personalidade do homem e 0 animus o componente masculino na personalidade da mulher. Não existe homem algum que seja exclusivamente masculino nem mulher alguma exclusivamente feminina. Todavia, o homem geralmente reprime da melhor maneira possível seus traços femininos, da mesma 
forma que a mulher considera inconveniente ser máscula e varonil. Esses traços reprimidos acumulam-se no inconsciente.

No homem, o receptáculo destas pretensões constitui a imago da mulher, uma espécie de imagem virtual à qual Jung denominou anima. É a anima que orienta as escolhas amorosas, pois o homem buscará a mulher que melhor corresponda à sua feminilidade inconsciente. $\mathrm{O}$ mesmo ocorre com a mulher em relação ao animus. Como expõe Sanford (1997), os homens identificados com sua masculinidade, tipicamente projetam seu lado feminino sobre as mulheres, e as mulheres projetam seu lado masculino sobre os homens. A projeção é um mecanismo psíquico inconsciente que ocorre quando um aspecto vital desconhecido da nossa personalidade é ativado. Diz: "quando algo é projetado, vemo-lo fora de nós, como se fizesse parte de outra pessoa e nada tivesse a ver conosco" (p. 17). A pessoa que carrega a imagem proje- tada passa a ser muitíssimo supervalorizada ou muitíssimo desvalonizada, causando-nos atração ou repulsa, ficando assim obscurecida a imagem real do indivíduo.

Quando o homem e a mulher projetam suas imagens positivas simultaneamente um sobre o outro, ocorre o estado de fascinação recíproca do estar apaixonado (Figura 2). Nesse estado, existe um relacionamento a nível consciente entre as personalidades do ego do homem e da mulher (setas A). Existe também, como foi dito, uma forte atração decorrente da projeção da anima do homem sobre o ego da mulher e a projeção do animus da mulher sobre o ego do homem (setas B). Contudo, a fonte do magnetismo do estar apaixonado reside na atração totalmente inconsciente entre anima e animus (setas C), como se a anima do homem e o animus da mulher estivessem completamente apaixonados um pelo outro, e é por isso que Sanford (1987) denomina-os de parceiros invisíveis.

\section{Figura 2. Esquema de Projeção em um Relacionamento Amoroso}

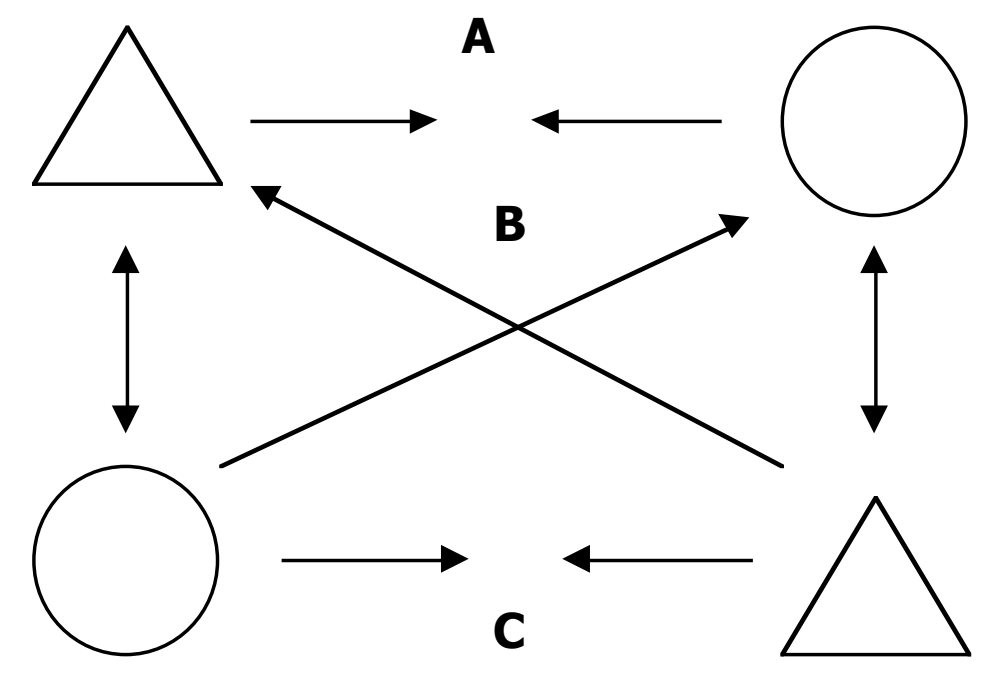

Fonte: Sanford, 1997, p. 27

O relacionamento amoroso pode propiciar a polaridade com o inconsciente mais profundo de cada um, depois que o Ego já está estruturado. $\mathrm{O}$ Ego passa a se relacionar com o arquétipo do animus-anima, que já vinha se manifestando nos namorinhos de infância e adolescência. É, porém, na fase adulta que o arquétipo do animusanima é muito ativado, levando o indivíduo à busca do cônjuge. Dentro do processo de individuação, cada um deve passar por vivências pelas quais integre este arquétipo.

Para Vargas (1981), na dinâmica arquetípica da escolha do parceiro, a busca é parcialmente inconsciente, presidida pelos arquétipos do animus e da anima, onde, freqüentemente, são os opostos que se atraem. Um cônjuge tem na 
consciência o que o outro tem por se desenvolver, no inconsciente. Fundamentalmente, a personalidade busca o desenvolvimento da sua outra metade. Assim, o homem que tenha predomínio de um dos princípios (masculino ou feminino) tenderá a se sentir atraído por uma mulher com predomínio do princípio oposto na sua consciência.

O mesmo fenômeno ocorre em relação à tipologia psicológica. Assim sendo, aquele que tem o pensamento como função superior consciente tenderá a sentir-se atraído por uma parceira cuja função principal seja o sentimento, pois é exatamente esta a sua função menos desenvolvida, ou seja, sua função inferior inconsciente. Analogamente, o tipo sensação sentir-se-á atraído pelo tipo intuitivo e o tipo extrovertido tenderá a sentir-se atraído pelo tipo introvertido.

\section{Tipos de Conflitos na Relação Conjugal}

Devido à nossa cultura patriarcal, o homem torna-se depositário do princípio masculino, sendo identificado com ele, e a mulher identificase e torna-se depositária do princípio feminino. Essa deposição exagerada do princípio masculino no homem e feminino na mulher gera muitos distúrbios e conflitos na relação conjugal. Assim, a mulher sente-se na obrigação de agradar, de atrair, de fazer com que o homem se apaixone por ela, enquanto o homem sente-se na obrigação de conquistar, de buscar, de possuir. Se o homem propõe que a mulher escolha o que vão fazer ou espera que ela tenha iniciativa, ela pode senti-lo como "desinteressado". Por outro lado, a mulher que toma iniciativas e faz propostas pode ser vista como mandona e sentida como uma ameaça, pois pode almejar o poder sobre o homem e sufocá-lo.

Não existe relacionamento conjugal sem conflitos. Alguns casais passam por mais conflitos, outros menos, mas toda relação conjugal passa por conflitos e crises. Para Jung (citado por Vargas, 1981), entretanto, o critério para um relacionamento saudável não é a quantidade de conflitos e sim 0 desenvolvimento da individuação, ou seja, o importante é saber se a vivência conjugal está propiciando ou não a individuação dos parceiros.

O casamento representa, na nossa cultura, uma das situações mais ricas para a vivência das polaridades e, portanto, para o desenvolvimen- to da polaridade de cada um dos cônjuges. Entretanto, a união dos opostos pode ser criativa ou patológica. Na união criativa, a relação entre os opostos tipológicos dá-se em uma vivência dialética criativa, onde, segundo Vargas (1981), “Um ajuda o outro a desenvolver-se naquilo que tem de menos desenvolvido, ou seja, na sua função inferior, o que implica na diminuição do predomínio tão grande da superior. Cada um integra ao seu consciente aspectos negados, rejeitados ou não desenvolvidos e com isto o Ego e a personalidade com um todo crescem e se desenvolvem em busca de sua individuação" (p. 31).

Podemos observar que enquanto o relacionamento estiver na fase da paixão, sempre teremos uma situação de simbiose entre os cônjuges. Essa simbiose poderá evoluir de maneira criativa e integradora, ou então tornar-se uma união completamente patológica, constituindo uma simbiose conflitiva. Conforme Byington (citado por Vargas, 1981), a simbiose conflitiva pode apresentar-se de duas formas: simbiose conflitiva criativa e simbiose conflitiva dissociativa.

A simbiose conflitiva criativa caracterizase pela união das funções tipológicas e das características latentes criativas complementares. Essa relação é simbiótica porque o marido delega à esposa e ela desempenha a sua função inferior, enquanto a esposa, por sua vez, delega ao marido e ele desempenha a função inferior dela. Cada cônjuge cobre as deficiências do outro, podendo gerar até uma unidade aparentemente feliz de bemestar, mas não constitui uma união criativa e integradora porque não propicia a individuação dos parceiros. Essa relação é conflitiva porque, embora seja confortável delegar ao outro as funções que não desempenha tão bem, a pessoa sente-se frustrada por seu cônjuge na medida em que este, ao desempenhar estas funções de maneira tão mais espontânea e fácil, inibe suas possibilidades de desenvolvê-las por si mesmo. Entretanto, essa simbiose conflitiva é classificada como criativa porque um cônjuge vivencia no outro o seu potencial criativo, aquilo que ele tem por se desenvolver.

Muito diferente é a simbiose conflitiva dissociativa. Nessa relação, um cônjuge vivencia no outro suas partes inaceitáveis e sombrias. Assim sendo, a simbiose conflitiva dissociativa caracteriza-se pela mútua projeção das sombras, onde cada cônjuge dissocia-se de seus conteúdos inconscientes, inclusive de suas funções inferiores, pro- 
jetando-os no seu parceiro que é então atacado de maneira terrível e destruidora. Essa relação constitui uma união patológica, onde "o objetivo de minha paixão tem características que eu abomino e rejeito, mas é justamente por aquela 'porcaria' que eu me apaixono" (Vargas, 1981, p. 121). A ligação é mórbida, repetitiva e compulsiva, sem nenhuma criatividade, em total e mútua dependência. $\mathrm{O}$ casal passa a vida toda se agredindo, se destruindo, mas não se separa. "Cada cônjuge funcionará como tela das projeções de tudo que está inconsciente e dissociado do outro e, portanto, de todo o lado mais sombrio de cada um" (Vargas, 1981, p. 32).

\section{Método}

O método da pesquisa consistiu em um estudo de caso, tendo um casal como amostra. O criténo para a escolha do casal foi o tempo de casamento, sendo que os sujeitos escolhidos estavam casados há 42 anos. Partimos do pressuposto de que, quanto maior a duração do casamento, maior a possibilidade de um casamento harmônico.

Para pesquisar a dinâmica do casal, utilizamos a entrevista oral semi-estruturada, como técnica de investigação. Após a aplicação individual do QUATI, fizemos a entrevista com cada cônjuge separadamente. A análise dos resultados foi dividida em: quantitativa e qualitativa.

Na análise quantitativa, nós verificamos e comparamos as pontuações obtidas pelo casal no teste QUATI, demonstradas sob a forma de tabelas e diagramas abrangendo a relação entre as quatro funções.

Na análise qualitativa, comparamos os relatos que estes fomeceram na entrevista oral semi-estruturada (realizada antes da aplicação do teste), confrontando-os com as respostas do QUATI e com o referencial teórico dos tipos psicológicos junguianos.

Finalmente, para compreender a influência dos tipos psicológicos na dinâmica deste casal, fizemos uma análise da dinâmica do casal, comparando as análises individuais de cada cônjuge (quantitativa e qualitativa) e confrontando com o referencial teónico utilizado.

\section{Resultados}

O marido tinha 62 anos de idade e a esposa 61. Tinham dois filhos e duas netas. Na en- trevista, relataram que se conheceram quando tinham 20 e 19 anos, respectivamente. Ambos eram fisicamente muito bonitos. 0 marido trabalhava em uma ótica e a esposa era secretária de uma companhia de seguros. Seu nível socioeconômico, na época, era de classe média baixa. O marido só estudou até a 2. ${ }^{\text {a }}$ série do Ensino Médio, sendo que nenhum deles fez curso superior.

Nove meses depois já estavam casados e a esposa grávida do primeiro filho. Como as condições de posse eram pequenas, foram morar na casa da mãe do marido. Dois anos depois, a esposa parou de trabalhar. Assim, começaram a haver conflitos entre a esposa e sua sogra, por isso, após alguns meses, resolveram alugar uma casa. Ainda nessa época, o marido cantava e foi contratado pela emissora de rádio e televisão Record e isso não agradava a esposa, porque as mulheres o assediavam muito. Então, o marido preferiu parar de cantar e dedicar-se à família.

O marido passou a ser muito trabalhador, praticamente um "workaholic". De empregado tornou-se proprietário e cresceu muito financeiramente. Hoje as condições de posse deles são muito boas.

Segundo as entrevistas dos dois, eles nunca passaram por um período de crise no casamento, nem tiveram nenhuma grande discussão, apenas algumas briguinhas de ficar sem se falar por uns dois dias. Os dois enfatizaram isso muitas vezes durante a entrevista. Mesmo assim, a esposa nos revelou que o marido tivera alguns "casinhos" extraconjugais, mas que ela relevou por ele ser um bom marido e um bom pai.

Pelo relato do marido, podemos perceber tendências metódicas e sistemáticas, devido a seu gosto de ter as coisas todas rigorosamente em ordem, sendo que ele mesmo julga-se teimoso e chato, atribuindo a isso um ataque cardíaco que teve. Segundo a esposa, depois disso, ele mudou bastante, tornado-se mais quieto, mais tranqüilo e mais caseiro. A esposa, no entanto, continua gostando de sair, mas como o marido prefere ficar em casa, ela aproveita para fazer as coisas de que gosta quando ele está viajando.

Realizamos, além da entrevista, a aplicação do teste QUATI para uma melhor compreensão da tipologia de cada um. Assim, comparando os resultados do casal, obtivemos: 
Tabela 1. Tabela Comparativa de Resultados da Aplicação do QUATI no Casal.

\begin{tabular}{|l|l|r|l|c|}
\hline & Marido & \multicolumn{2}{l|}{ Esposa } \\
\hline Atitude & Extrovertido & 5 & Extrovertido & 22 \\
\hline Função Principal & Sensação & 12 & Sentimento & 10 \\
\hline Função Auxiliar & Sentimento & 4 & Sensação & 5 \\
\hline
\end{tabular}

Representando a tipologia pelos diagramas da quaternidade, obtemos:

\section{Tabela 1. Diagrama Cruciforme da Tipologia do Casal}

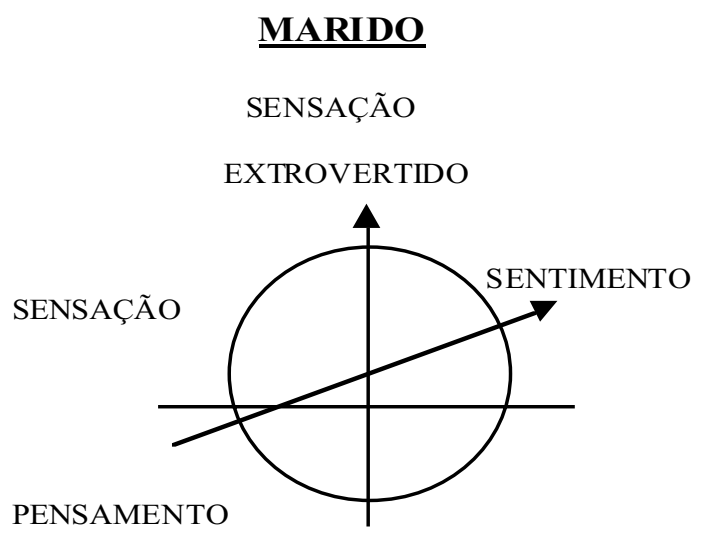

INTUIÇÃO

INTROVERTIDO

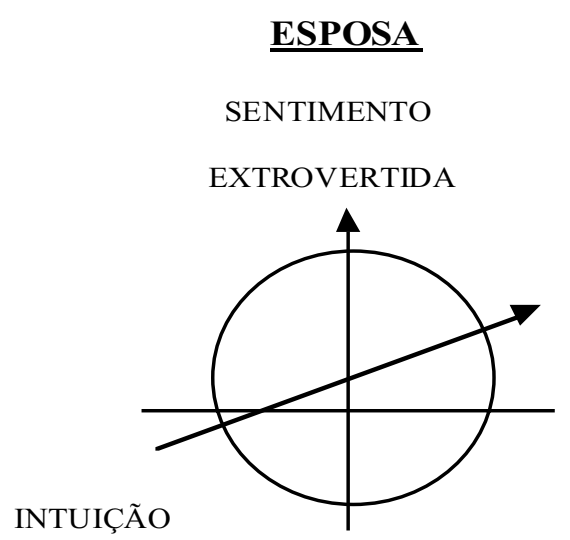

PENSAMENTO

INTROVERTIDO

\section{Discussão}

Observando os diagramas, o primeiro fator que nos chama a atenção é o de que o marido e a esposa não constituem opostos tipológicos, 0 que significa que, segundo a teoria junguiana, eles não representam tipos opostos ideais. Mesmo assim, são casados há 42 anos e, segundo dizem na entrevista, possuem um casamento tranqüilo, pacífico, harmônico, quase sem discussões e brigas.

Então, como se explica esse relacionamento tão harmônico e duradouro? Para responder a isso é preciso ressaltar aqui duas coisas: primeiro, conforme foi explicado anteriormente, para Jung, o critério para um relacionamento saudável não é a quantidade de conflitos (ou oposição) e sim 0 desenvolvimento da individuação, ou seja, o importante é saber se a vivência conjugal está propi- ciando ou não a individuação dos parceiros; e segundo, o fato dos cônjuges não serem opostos tipológicos significa que eles não funcionam como opostos intrapsíquicos.

Vamos começar analisando a atitude. Apesar de ambos possuírem uma atitude extrovertida, a esposa apresentou pontuação 22, enquanto o marido apresentou apenas 5 pontos, havendo, portanto, uma diferença de 17 pontos! Apesar de a atitude geral ser a mesma (Extroversão), provavelmente, ao se relacionarem um com o outro, 0 marido deve achá-la extrovertida demais e a esposa, apesar dele ser extrovertido, deve achá-lo introvertido.

Podemos comprovar isso analisando algumas respostas do QUATI. Na área de lazer, por exemplo: se alguém convida a esposa para sair, ela aceita imediatamente; se alguém convida 0 
marido, ele prefere convidá-lo para ficar em sua casa. Em viagens, a esposa prefere viajar em um grupo grande de pessoas, enquanto o marido gosta de viajar em um pequeno grupo de pessoas. Observamos no teste que o marido apresenta respostas de atitude introvertida em todas as áreas, mas o mesmo não ocorre com a esposa, pois não apresenta nenhuma resposta introvertida nas áreas de festa, lazer e vida pessoal. Assim sendo, em termos de atitude, o marido funciona como um oposto intrapsíquico para a esposa em muitas situações. Curiosamente, o marido descreve-se no início do namoro como muito extrovertido e a esposa confirma dizendo que ele mudou muito.

A nossa compreensão da dinâmica deste casal é a de que, hoje, eles têm uma relação mais saudável. Como apontamos na análise do marido, provavelmente ele fez um caminho da Extroversão para a Introversão. Se ele mantivesse um tipo muito Extrovertido, possivelmente a relação não duraria tanto, porque não promoveria a individuação dos parceiros.

Se a atitude é a mesma (Extroversão), no início do relacionamento o casal fica muito empolgado, porque ambos gostam de sair, viajar, ir a festas, churrascos, cinema etc. Com o tempo o relacionamento ficaria vazio, porque ambos seriam muito parecidos e um não completaria o outro. $\mathrm{O}$ que completa uma pessoa não é aquele que é igual a ela, mas sim aquele que é diferente, que tem algo que o outro não tem. O que nos completa é aquilo que nos falta para desenvolver. Se ambos forem iguais, um não terá nada a ensinar ao outro e aquilo que um não tem desenvolvido, o outro não tem como ajudar a desenvolver. Em uma relação de iguais há pouco crescimento pessoal, que não facilita o processo de individuação.

Analisando as funções da consciência, podemos dizer que a função mais desenvolvida e utilizada pelo marido é a Sensação. Para ele, o oposto tipológico ideal é a Intuição. Como a esposa é Sentimento, o casal não constitui opostos tipológicos ideais. Entretanto, em três das seis áreas da vida da esposa (trabalho, lazer e vida pessoal), a Intuição prevalece sobre a Sensação.

Por exemplo: no trabalho, o marido gosta da rotina de trabalho e se apega a ela, pensando na maior praticidade e operacionalidade do trabalho. A esposa, por outro lado, constantemente pensa em inovações e mudanças na rotina e aprecia participar de novas tarefas e projetos inovado- res. No lazer, o marido geralmente faz coisas habituais, enquanto a esposa deixa que a inspiração imediata diga o que deve fazer. O marido utiliza o tempo livre em atividades manuais ou de utilidade imediatas, enquanto a esposa prefere utilizar este tempo livre para planejar atividades futuras.

Passemos agora para o caso da esposa. A função superior dela é o Sentimento, portanto o tipo oposto ideal é o Pensamento. Embora a função superior do marido não seja Pensamento, ele apresenta respostas do tipo Pensamento em todas as áreas e em quantidades nada desprezíveis.

Vejamos alguns exemplos de situações onde o marido apresenta respostas de tipo Pensamento, enquanto a esposa responde como Sentimento: em festas, a esposa procura ressaltar os pontos positivos da festa, para quem a promoveu, enquanto o marido, por outro lado, não se importa em criticar até mesmo o dono da festa, se isso for necessário. No trabalho, o marido costuma ser lógico e impessoal nas suas decisões profissionais, enquanto a esposa costuma ser sensível aos sentimentos dos colegas nas suas decisões. Nas viagens, o marido organiza o roteiro da viagem de maneira lógica e objetiva e a esposa organiza 0 roteiro da viagem tomando por base o que mais gosta de fazer. Nos estudos, em trabalhos de grupo, o marido é mais questionador e crítico, enquanto a esposa é mais conciliadora e pacificadora. No lazer, o marido recusaria um convite feito por um amigo, explicando as razões, enquanto a esposa teria dificuldade em recusar um convite feito por um amigo. E finalmente, na vida pessoal, o marido se considera consistente e razoável nas suas idéias, enquanto a esposa se considera profunda nos seus sentimentos.

Assim, podemos verificar que, em diversas situações, de todas as áreas, o marido se comporta de maneira oposta à esposa, formando uma complementaridade tipológica. Resta-nos agora saber em que tipo de relacionamento podemos classificá-los.

Como descrevemos anteriormente, há três tipos de relacionamento conjugal: união criativa, simbiose conflitiva criativa e simbiose conflitiva dissociativa. Certamente o casal pesquisado não constitui uma simbiose conflitiva dissociativa, pois essa relação caracteriza-se pela mútua projeção das sombras, onde um cônjuge vivencia no outro suas partes inaceitáveis e sombrias, e é atacado de maneira terrível e destruidora. A ligação é mórbida, 
repetitiva e compulsiva, sem nenhuma criatividade, em total e mútua dependência. O casal passa a vida toda se agredindo, se destruindo, mas não se separa.

Seguramente, nosso casal não se enquadra neste tipo de relação. O relacionamento deles quase não tem brigas, um não agride o outro e nem sequer falam mal do parceiro. Existe, sim, uma relação simbiótica, porque eles interagem-se com uma certa dependência tipológica. No nosso entendimento, a relação é simbiótica porque 0 marido delega à esposa e ela desempenha a função inferior dele, enquanto a esposa, por sua vez, delega ao marido e ele desempenha a função inferior dela.

Por exemplo, no trabalho, o marido gosta da rotina e faz coisas habituais, preocupando-se com a praticidade e operacionalidade das tarefas. A esposa, no entanto, gosta de fazer mudanças na rotina, planeja atividades futuras e implementa inovações. O marido costuma ser lógico e impessoal nas suas decisões profissionais, enquanto a esposa costuma ser sensível aos sentimentos dos colegas nas suas decisões. Assim, ambos complementam-se no trabalho, o que gera bons resultados profissionais, mas certamente essa complementação tipológica contribuiu muito para a prosperidade da empresa.

Cada cônjuge cobre as deficiências do outro, podendo gerar até uma unidade aparentemente feliz de bem-estar, mas não chega a constituir uma união criativa e integradora, porque não propicia a individuação dos parceiros ou então esse processo torna-se muito lento. Por exemplo: a esposa gosta de ir ao cinema, mas como o marido prefere assistir filmes em casa, ela deixa para ir ao cinema quando ele vai pescar. O que ela gosta de fazer, ela faz sozinha. Como ela diz na entrevista: "(...) enquanto ele vai pescar, ponho tudo em dia" (sic).

Concluindo, cada um delega ao outro suas funções não desenvolvidas, havendo pouco crescimento pessoal, o que dificulta o processo de individuação. Assim sendo, segundo nossa compreensão do caso analisado, a relação deste casal não é uma simbiose conflitiva dissociativa, mas também não chega a ser uma união criativa constituindo, portanto, uma relação simbiótica conflitiva criativa. Esta simbiose conflitiva é criativa porque um cônjuge vivencia no outro o seu potencial criativo, aquilo que ele tem por se desenvolver. Ca- racteriza-se pela união conflitiva das funções tipológicas e das características latentes criativas complementares.

\section{Considerações Finais}

Quando começamos a construir o projeto desta pesquisa, ficamos fascinados pela beleza do mito platônico, onde o personagem Aristófanes narra como os seres humanos primordiais foram divididos ao meio e por isso, desde então, homens e mulheres passam suas vidas em busca da unidade perdida.

Até o momento, pensávamos apenas no mito e no fenômeno comum de homens e mulheres procurando, como comumente dizem suas almas gêmeas, sua cara-metade, a tampa da panela, ou ainda, a metade da laranja. E em como essa união fazia o casal sentir-se como se fossem unos, fundidos em um só.

Quão surpresos ficamos quando começamos as leituras junguianas para o referencial teórico! Foi com assombro que descobrimos que, quando Jung fala em recuperar a unidade perdida, não está falando sobre relacionamento de casal, mas sim sobre a integração de si mesmo. Foi só então que compreendemos a profundidade do mito platônico. E também compreendemos por que Jung estudara tanto os mitos e como concebera a idéia dos arquétipos do inconsciente coletivo. Subjacente ao mito do homem buscando reintegrar-se à mulher, encontrava-se a idéia do homem tentando reintegrar-se a si mesmo, do homem procurando resgatar suas próprias partes perdidas, aquelas que foram deixadas à sombra, reprimidas no inconsciente. A busca da unidade perdida é a busca pela integração entre consciente e inconsciente, entre ego e sombra, entre função superior e inferior, entre princípio masculino e feminino, entre anima e animus.

Curiosamente, para que o casal consiga resgatar a unidade perdida, é necessário abandonar o projeto de formar uma unidade perfeita. Podemos resgatar a unidade perdida, mas essa unidade não se dá com o outro e sim por meio do outro. É pelo outro que podemos atingir a unidade conosco mesmo. Pela integração de aspectos idealizados projetados no outro, podemos restabelecer a conexão necessária entre ego e self. Eis o caminho da individuação, que nos ensina Jung. 
É somente pela busca pela nossa própria totalidade psíquica que nós conseguiremos, quem sabe um dia, resgatar a nossa tão desejada unidade perdida.

\section{Referências}

Fujii, S. M., Kamei, H. H. (2003). Em busca da unidade perdida: A influência dos tipos psicológicos na dinâmica de casal. Trabalho de Conclusão de Curso, Instituição Universidade São Marcos, São Paulo.

Hall, C. S. \& Nordby, V. J. (1980). Introdução à psicologia junguiana. São Paulo: Cultrix.

Henderson, J. L (1997). Os mitos antigos e o homem moderno. In: C. G. Jung (Org.) O homem e seus símbolos. (12a ed). (pp. 104-157). Rio de Janeiro: Nova Fronteira.

Jung, C. G. (1988). 0 desenvolvimento da personalidade Vol. 17. Obras completas de Carl G. Jung. (4a ed). Petrópolis: Vozes.

Jung, C. G. (1995). Psicologia do inconsciente. Vol. 7/1 Obras completas de Carl G. Jung. (10a ed). Petrópolis: Vozes.

Jung, C. G. (2000). O Eu e o inconsciente. Vol. 7. Obras completas de Carl G. Jung. (14a ed). Petrópolis: Vozes.
Platão (1986). 0 banquete. Portugal: Europa-América.

Sanford, J. (1997). Os parceiros invisíveis: 0 masculino e o feminino dentro de cada um de nós. (4a ed). São Paulo: Paulinas.

Sharp, D. (1987). Tipos de personalidade: 0 modelo tipológico de Jung. São Paulo: Cultrix.

Vargas, N. S (1981). A importância dos tipos psicológicos na terapia de casais. Dissertação de Mestrado, Instituto de Psicologia, Universidade de São Paulo, São Paulo.

Von Franz. (1997). O processo de individuação. In: C. G. Jung (Org.) 0 homem e seus símbolos. (12a ed). (pp. 158-229). Rio de Janeiro: Nova Fronteira.

Zacharias, J. J. M. (1999). QUATI: Questionário de avaliação tipológica (versão III): manual. (3a ed. rev. e ampl.). São Paulo: Vetor.

Zacharias, J. J. M. (2006). Tipos: A diversidade humana. São Paulo: Vetor.

Recebido em/received in: 19/05/2006 Aprovado em/approved in: 02/10/2006 